\title{
Foreword
}

\section{The monitoring programme of the ecological and ecotoxicological consequences of the "Erika" oil spill}

\author{
Lucien Laubier ${ }^{1,2}$, Morgan Le Moigne ${ }^{2,3, a}$, Patrick Flammarion ${ }^{2,4}$, Eric Thybaud ${ }^{2,5}$ and Daniel Cossa ${ }^{2,3}$ \\ ${ }^{1}$ Director of the Oceanographic Institute of Paris /President of the Scientific Oversight Committee \\ 2 Erika Scientific Steering Committee \\ 3 IFREMER, BP 21105, 44311 Nantes Cedex 3, France \\ 4 Ministry of Ecology and Sustainable Development, Department of Economic Studies and Environmental Assessment \\ 5 INERIS, Paris, France
}

On December 11, 1999, Erika, an oil tanker flying the Maltese flag and loaded with $31000 \mathrm{t}$ of heavy fuel oil, was making its way from Dunkirk to Livorno when it encountered difficult weather conditions Southwest of the Brittany coast (gale force winds 8 to 9 and 6 m waves). On the morning of the 12th December, the captain broadcast an SOS; his vessel was breaking in two, approximately 30 nautical miles to the south of Penmarc'h Point (Fig. 1; Finistère, France). The fore section of the vessel sank during the night of the 12-13 December and the aft section was taken in tow on the morning of December 13, but subsequently sank in the early afternoon. Both parts lay in $120 \mathrm{~m}$ of water and were located $10 \mathrm{~km}$ apart. Approximately, $19000 \mathrm{t}$ of heavy fuel oil were spilled into the sea. The first of the fuel oil came ashore on December 23 and the major strandings took place between December 24 and 27. The Loire Atlantique and Vendée coasts were severely contaminated and the départements of Finistère, Morbihan, and Charente Maritime in the South, were in no way spared. Violent winds blowing at right angles to the coast accompanied by extremely high tides washed the pollution high up the beach strand, reaching the tops of cliffs more than $10 \mathrm{~m}$ high.

The struggle at sea against the pollution began on December 15 and $1200 \mathrm{t}$ of fuel were recovered within the next fortnight. Between mid May and late summer 2000, a little more than $10000 \mathrm{t}$ of heavy fuel oil were fluidised by adding colza methyl ester and pumped from the tanks of the sunken vessel, while an additional $1200 \mathrm{t}$ were pumped out during final cleaning.

A total of $12400 \mathrm{t}$ of the originally transported $31000 \mathrm{t}$ were retrieved from both the sea and the wreck and a little less than $19000 \mathrm{t}$ were released into the environment. In addition, the cleaning of the contaminated coasts that took

\footnotetext{
a Corresponding author: Morgan.Le.Moigne@ifremer.fr
}

place throughout 2000 and 2001 removed a total of 240000 to $280000 \mathrm{t}$ of polluted material (according to sources) containing 30000 to $40000 \mathrm{t}$ of emulsion (with $30-50 \%$ seawater) and therefore more or less equalling the amount of oil spilled.

\section{The monitoring programme}

The monitoring programme that studied the ecological and ecotoxicological consequences of the Erika oil spill aimed to implement well established methodologies rather than to develop new ones. This programme was launched by the French Ministry of Ecology and Sustainable Development (MEDD) and steered by a committee consisting of elected representatives, administrations and associations. The management of the programme was undertaken by IFREMER (French Research Institute for the Exploitation of the Sea) and INERIS (National Institute for Environment and Industrial Risks). A scientific oversight committee with independent European scientists as members provided the expert appraisal. Open for tender until 2002, the call for proposal comprised four different topics:

1. The spatial and temporal extent of the contamination and its spread along the coast.

2. The transformation and bio-availability of contaminants.

3. The impact on living organisms, including the impact on both supralittoral and intertidal species.

4. The monitoring of the clean-up operation and the restoration of the coastline.

Thirty research projects proposed by Universities, Research Institutes and Associations were selected and funded. Seven of these projects focused on the chemical monitoring of contamination of the water column, rocky 


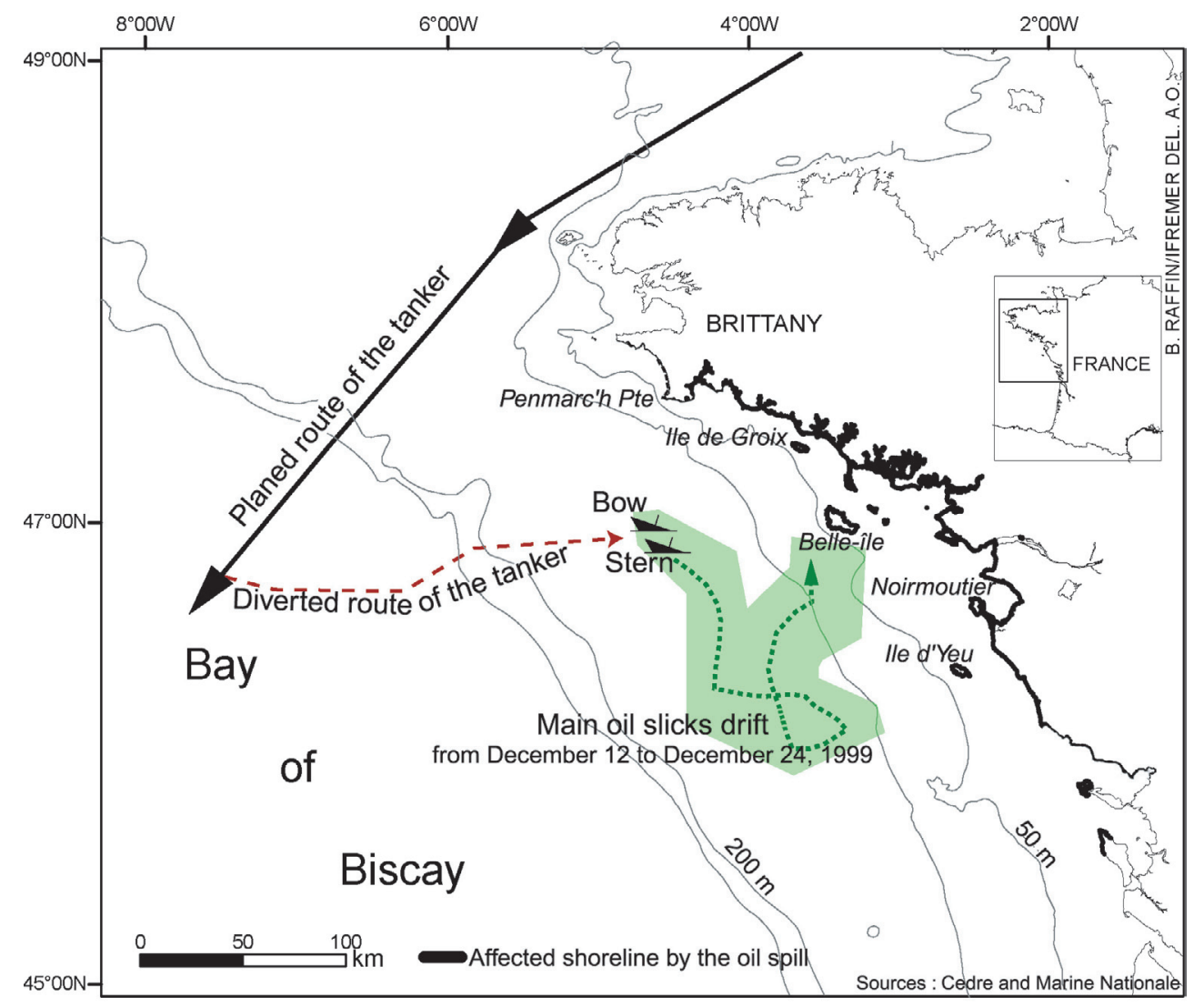

Fig. 1. Map showing the spatial extent of the Erika oil spill; affected shoreline in bold.

shore, sediments and organisms. Seven projects dealt with the impact of the oil slick on birds and sea mammals. Fifteen projects covered marine fauna and marine and coastal flora. Lastly, a project undertaken recently (in 2003) analysed the modifications to the coastline brought about by cleaning operations (see the website: www . suivi-erika.info).

\section{The main findings}

The degradation of the Erika's oil was studied in an intertidal environment on different types of substrate. A preliminary laboratory study had shown that the biodegradation of this heavy fuel oil was an extremely slow process. In the natural environment of the intertidal zone, significant light exposure speeds up the photo-oxidation of the oil. The impact of the oil on microbial mats collected within salt marshes was also investigated and yielded strains of bacteria capable of biodegrading model hydrocarbon molecules.

From the time of the disaster until late 2003, the chemical contamination of water, marine sediments, salt marshes, and intertidal bivalves was monitored, using polycyclic aromatic hydrocarbons (PAH) as tracer molecules. In the most contaminated areas (the Loire Atlantique and Vendée coasts), the PAH concentrations measured in the soft tissues of bivalves led to a ban on shellfish collection and shellfish farming which remained in place until early 2001. For the sum of the 16 priority PAH from the list selected by the United
States Environmental Protection Agency, the French Agency for Food Health and Safety (AFSSA) had set a guideline value of $500 \mu \mathrm{g} \mathrm{kg}^{-1}$ dry weight, and the Directorate of Sea Fishing and Farming (DPMA) then set an exclusion threshold at twice this concentration. The maximum concentration of 3000 to $5000 \mu \mathrm{g} \mathrm{kg}^{-1}$ (dry weight) was recorded near Le Croisic and on the west coast of Noirmoutier Island. The National Monitoring Network for the Quality of the Marine Environment (RNO), a long term monitoring network supported by the MEDD and conducted by Ifremer, allows a comparison to be made between the post-spill contamination and the chronic level of contamination (100 to $200 \mu \mathrm{g} \mathrm{kg}^{-1}$ dry weight for the sum of 16 priority $\mathrm{PAH})$.

Particular attention was paid to the vanadium and nickel levels as tracers of the Erika fuel oil. In filter-feeding mussels and oysters, an abrupt rise in vanadium concentrations was recorded in May 2000, five months after the shipwreck. Higher levels of nickel and metallothioneins were noticed at several sites. Other studies were also carried out on species with different feeding habits, i.e., the periwinkle Littorina littorea, the dog whelk Nucella lapillus, the starfish Asterias rubens and populations of benthic foraminifera, etc.

The littoral plant communities were monitored for a 4-year period, using phytosociological analyses and the study of oil products in the plant tissues. The development of the plants did not appear to be significantly affected by the impact of the spill except at seriously polluted sites where the vegetation was totally covered with oil. The PAH concentrations found in 
the plant tissues are gradually decreasing over time. Areas that had undergone cleaning operations were affected to extremely varying degrees in terms of plant cover and the floral species diversity.

Marine birds wintering in the Bay of Biscay were by far the most affected by the oil spill. The common guillemot Uria aalge was the most impacted species: in the first month following the disaster, 64000-125000 guillemots died, of which one-third were less than one-year old. Records suggest that the seabird populations did not decline in the 2 years after the disaster. Analyses of ring recoveries and biometry indicated that guillemots in the affected area originated from a large geographic area, including colonies from across the British Isles and the North Sea, along with more northern localities. A genetic approach using microsatellites showed little genetic differentiation among Northeastern Atlantic guillemot colonies.

The oiled bird rehabilitation centres released approximately 2500 cleaned birds, of which 100 were later found dead. For a quantitative assessment, counts were carried out using both boats and aircraft. These results allowed the identification of sensitive sectors and changes in the spatial distribution of the sea birds. Aircraft observations minimized the intrinsic statistical difficulties in surveys carried out using vessels.

No marine mammals were found to have died as a result of the oil spill. Grey seals and dolphins displayed no symptoms related to the oil spill. The only noticeable effects were change in porphyrin levels and nickel/vanadium ratios in the faeces of the otter Lutra lutra.

Marine invertebrates were particularly affected by the pollution. Initially, there was widespread mortality of sensitive species such as sea urchins, which was followed by local ecological succession processes. Overall, the impact of the spilled oil on the invertebrate communities and populations could hardly be distinguished from the natural variability and heterogeneity of the environment and from the effects of long term anthropogenic disturbances. A subaquatic study, conducted in the Bay of Concarneau, the Archipelago of Glénan, the lsland of Groix and Belle-Ile failed to reveal any consequence from Erika pollution on the biodiversity of invertebrate populations. Of particular note were the immunopathological lesions found in the oyster Crassostrea gigas around Le Croisic, an area which was very badly affected by beached fuel oil.

A benthic fish, the sole, Solea solea, was selected as a model fish species. Although no direct mortality was observed, nor any necrosis on the ventral side (as was the case with the flat fish living in the Benoit and Wrac'h estuaries following the "Amoco Cadiz" oil spill) a multidisciplinary approach, combining observation and experimentation, provided the validation of certain biological markers of functional integrity at the individual scale, but effects were not detectable at the population level. The bio-accumulation and transformation of certain PAH was monitored. Thus, bile metabolites, in Solea solea, can be used as markers of exposure and identified 1hydroxypyrene as the major metabolite in bile, after enzymatic deconjugation.

Finally, the morphological impacts of the oil spill on the coast and the consequences of decontamination techniques are being studied, in order to minimise excessive interventions that endanger the littoral environment and to find alternative solutions that will preserve the ecological equilibrium.

\section{Conclusion}

In summary, this programme gave a better insight into the impact of the Erika oil spill on different areas of the littoral ecosystems, as well as serving to develop various chemical and biological markers. However, the research teams have been faced with one major problem of interpretation, i.e., a lack of knowledge about the structure and functioning of ecosystems in "normal" time, prior to the oil spill. How can one demonstrate the effects of severe pollution when the effects of chronic pollution remain an unknown factor? How may a change in the ecosystem caused by an oil spill be distinguished from natural developments related to climate change? A plethora of temporal and spatial variables make the interpretation of the effects a rather trying ordeal, especially when one considers the duration and the time scale in which marine populations and ecosystems evolve. The natural variability inherent in the populations introduces considerable uncertainty into the assessment of the impact and the recolonization following accidental pollution. In order to evaluate the effects of oil spill in the marine environment and the restoration of ecosystems, a minimum of knowledge of the structure of populations is a prerequisite. Moreover, appreciating the influence of climatic change over a 10-year period, means that one cannot expect communities and ecosystems ever to fully return to their pre-accident status.

For this reason, the implementation of new littoral observation networks focusing on living biota and communities and the strengthening of existing monitoring networks is a logical follow-on to this programme. In addition, the ex-post ecological states of a pollution incident and the ex-ante states of reference are indispensable. This systematic observation is a tool that allows new knowledge to be gained, with the ability to model it. The final round table session held during the Nantes symposium highlighted the significance of a strong connection between research and monitoring at the international level (e.g. the Global Monitoring for Environment and Security). This is the EU's water framework directive (2000/60 CE) which compels member states "to establish the environmental quality of surface waters as regards chemical status which needs to be reached by 2015 ". 